\title{
CADASTRAL RESURVEY USING HIGH RESOLUTION SATELLITE ORTHO IMAGE - CHALLENGES: A CASE STUDY IN ODISHA, INDIA.
}

\author{
P.K.Parida, M.K.Sanabada and S. Tripathi \\ Odisha Space Applications Centre, Bhubaneswar (ORSAC), Odisha \\ pkparida@yahoo.com, $\underline{\text { m_sanabada@yahoo.co.in and sandeeptrip.ifs@gmail.com }}$
}

KEY WORDS: GIS, Ortho-image, Geo-referencing, High resolution, Accuracy

\begin{abstract}
:
Advancements in satellite sensor technology enabling capturing of geometrically accurate images of earth's surface coupled with DGPS/ETS and GIS technology holds the capability of large scale mapping of land resources at cadastral level. High Resolution Satellite Images depict field bunds distinctly. Thus plot parcels are to be delineated from cloud free ortho-images and obscured/difficult areas are to be surveyed using DGPS and ETS. The vector datasets thus derived through RS/DGPS/ETS survey are to be integrated in GIS environment to generate the base cadastral vector datasets for further settlement/title confirmation activities. The objective of this paper is to illustrate the efficacy of a hybrid methodology employed in Pitambarpur Sasana village under Digapahandi Tahasil of Ganjam district, as a pilot project, particularly in Odisha scenario where the land parcel size is very small. One of the significant observations of the study is matching of Cadastral map area i.e. 315.454 Acres, the image map area i.e. 314.887 Acres and RoR area i.e. 313.815 Acre. It was revealed that $79 \%$ of plots derived by high-tech survey method show acceptable level of accuracy despite the fact that the mode of area measurement by ground and automated method has significant variability. The variations are more in case of Government lands, Temple/Trust lands, Common Property Resources and plots near to river/nalas etc. The study indicates that the adopted technology can be extended to other districts and cadastral resurvey and updating work can be done for larger areas of the country using this methodology.
\end{abstract}

\subsection{Introduction}

Generation of Cadastral maps is possible through High-tech survey methods using Ortho-images, DGPS and ETS. Cadastral boundary vectors obtained from ortho-images are used as base maps and obscured/difficult areas (not delineated/mapped from ortho-images) are surveyed using DGPS and ETS. The vector datasets thus derived through RS/DGPS/TS survey are integrated in GIS environment to generate the base cadastral vector datasets for further settlement/title confirmation activities. This exercise is undertaken to demonstrate the efficacy of the hybrid technology for cadastral map preparation. The project was conducted in Pitambarpur Sasana village under Digapahandi Tahasil of Ganjam district, Odisha.

\subsection{The objective of the project}

- To generate cadastral maps by using hightech survey methods using ortho-images, DGPS and ETS.

- To store the cadastral maps in digital format (storing \& updating cadastral maps using state-of-art technology) and to use this as base for all type of revenue administration and development planning.

- Deriving lat-longs of cadastral maps, its mosaiking and Geo-referencing to generate Land Information System (LIS) for Tahasils.
- To use GIS applications for plot level RoR, land use and infrastructure information generation using digital cadastral database.

3.0

\section{Study Area}

The Pilot Study was under taken in Pitambarpur Sasana village of Digapahandi Tehasil, Ganjam District. The total area of Pitambarpur Sasana is 317 acres. The area is falling within the Survey of India Toposheet No. 74 A/11. Approximate coordinates of polygon bounding of the village are:-

Lower left corner- $19^{0} 20^{\prime} 30^{\prime \prime} \mathrm{N}, 84^{0} 35^{\prime} 00^{\prime \prime} \mathrm{E}$ Upper right corner- $19^{0} 23^{\prime} 00^{\prime \prime} \mathrm{N}, 84^{0} 39^{\prime} 00^{\prime}$ ' E

\subsection{Methodology}

The broad methodology adopted under this Pilot project is as follows: -

- Acquisition of digital stereo satellite data of World View-II.

- Establishment of GCP control network by DGPS.

- Generation of photogrammetric block.

- Ortho image generation

- Collection of existing cadastral maps \& Coding/Scanning/Digitization of maps

- Delineation \& confirmation of village boundary 
- Plot level vectorisation \& map generation from ortho image

- Integration of image derived vectors and cadastral vectors (DoLR map) / ROR linking

- Survey and mapping of difficult areas/ ground truth collection

- Integration of vectors and preparation of base maps

- Map/RoR printing (output generation)

- GIS Database Creation

\subsection{Acquisition of Digital Stereo Data}

Digital Stereo Data of World View-II, PAN was acquired through National Remote Sensing Centre, Hyderabad, Department of Space, and Govt. of India having spatial resolution of $.5 \mathrm{~m}$ for this study.

\subsection{Establishment of GCP control network by DGPS survey}

ORSAC has established a Ground Control Network named Primary and secondary at a spatial grid of $16 \mathrm{~km} \times 16 \mathrm{~km}$ and $4 \mathrm{~km} \times 4 \mathrm{~km}$ respectively with the placement of cemented pillars having its pillar numbers. Tertiary control points were also created within a visible distance from both types of control points to facilitate ETS survey in the study area. DGPS observation of 4 hours at the primary control point and 1 hour at the secondary point were recorded. The recorded DGPS observations were post processed and network adjustment was performed using fixed solution with triangulation closing limit of $5 \mathrm{~cm}$ in case of primary control network and $10 \mathrm{~cm}$ for the secondary network. The network adjusted values were provided in both geographic co-ordinate system as well as real world co-ordinate system i.e. Universal Trans Mercator (UTM) projection with WGS 84 Spheroid and WGS 84 datum. The triangulated GCP network is shown in fig-1 below.

\section{Fig 1}

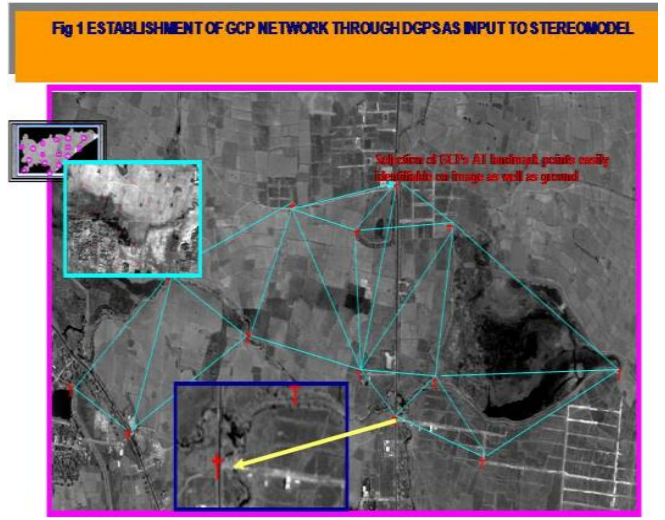

\subsection{Ortho image generation}

Leica Photogrammetry suite was used for generation of DEM as well as ortho-image for this study. This software uses block triangulation procedure taking the internal and external orientation using both sensor recorded DGPS observations from the header files of digital stereo pairs as well as GCPs taken from the study area. The RMS for the triangulation was .3 pixels. DEM of spatial resolution of $2 \mathrm{~m}$. was created which was then edited properly to create a good surface image. The orthoimage was created using the raster DEM as well as digital stereo pair images of spatial resolution of .5 meter. The process flow diagram is given below in fig- 2 .

Fig 2

ORTHO IMAGE PREPARATION USING LEICA PHOTOGRAMETRIC SUITE

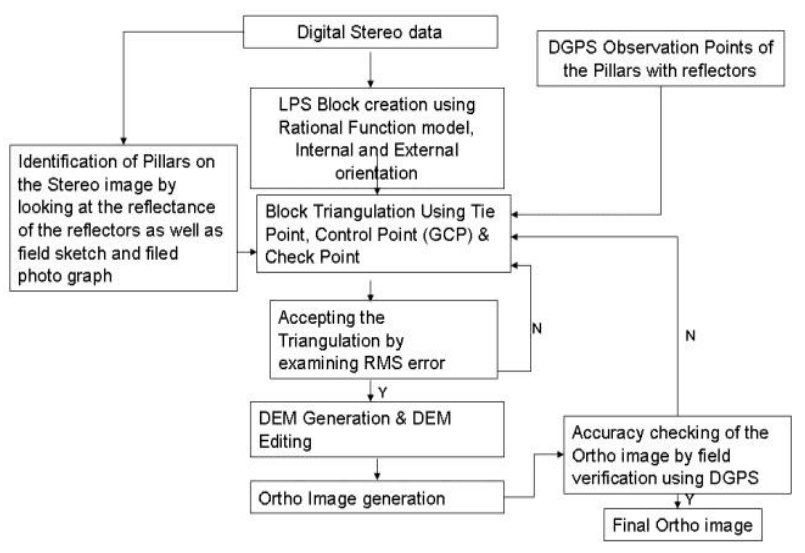

\subsection{Collection of cadastral maps \& Coding/Scanning/Digitization of maps}

Cadastral maps of the study area (Pitambarpur Sasana mouza) (maps in 1:2000 scale) were collected from the Directorate of Land Records and Survey, Cuttack. Maps collected in sheets were scanned after quality checking of each sheet with regard to its physical condition, readability, content and clarity. Maps were tiled on $100 \mathrm{mx} 100 \mathrm{~m}$ dimension of grid cells. All the four cadastral map sheets were digitized as per the guidelines of Department of Space. Hardcopy printouts are taken for 1 to 1 matching and quality assurance. After necessary quality check the existing cadastral maps are converted to GIS format for further georectification with orthoimages. The detail methodology is described in Fig. 3.

Fig 3

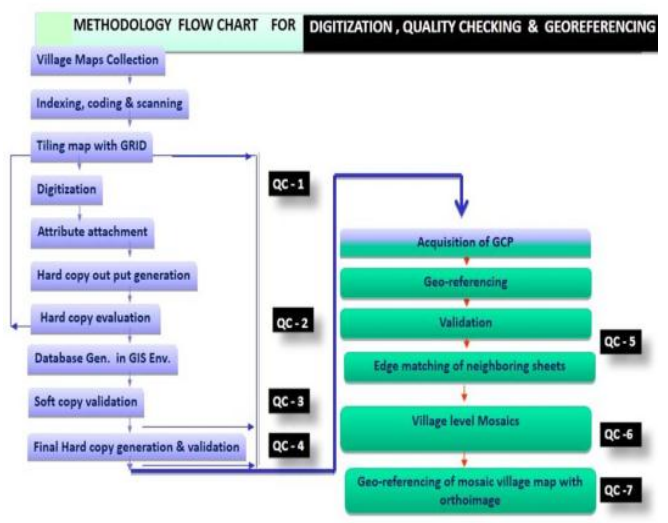




\section{5}

\section{Plot level vectorisation, map generation from orthoimage \& ROR linking}

The outer village boundary along with the location of bijunction and triunction points are extracted from digital cadastral map and transferred to the orthoimage by georeferncing the cadastral map with orthoimage. The field observations were taken using DGPS to confirm the outer boundary of the village and its coexistence with the neighboring mouza. The plot boundaries / vectors are interpreted by onscreen digitization method from enhanced Worldview orthoimage with precision following segmented approach i.e. the mouza divided into zones taking natural boundary into consideration and the sum of the area of the zones matching with ROR area. The vectors are drawn for the plots, which are clearly visible on the image in the first instance. The plots whose boundaries are obscured because of tree canopy and other reasons are not closed and left as it is. These difficult area polygons are finalized by field survey technique using DGPS and ETS. The habitation polygons, which are very small, are incorporated to the map from the existing cadastral map. A pre-field map was generated in 1:2000 scales for ground validation and DGPS based data collection. The pre-field map was used for ETS survey for the obscure areas where existing ground control coordinates were used for the measurement of coordinates in the obscure areas. The co-ordinates then transferred to the plot vector geo-database for the finalization of complete plot vector extraction of the mouza. The plot numbers were transferred from the geo-referenced cadastral map as well as from data collected from the tehesils for the mutated plots. ROR data for the mouza then linked with plot vector for finalization of the geodatabase.

\subsection{Survey and mapping of difficult areas/ ground truth collection}

DGPS observation was conducted in the field for establishment of a primary control point in the study area by a 12-hour observation. Simultaneous Observation for one hour was undertaken using a Rover for Secondary / Tertiary Control point. Further Ground control points were also retrieved by DGPS900 with real time processing capabilities at Pitambarpur Sasan village. Field verification was also conducted for the following locations.

- Field boundaries obscured by tree cover (Vertices closed by field measurements) Example of difficult areas is shown in Fig.4.

- Plot boundaries not clear on the image

- Govt. land under holding (cadastral plot showing subplots on image) by individuals

- Acquisition of plots (road and other infrastructure like Tank/ Canal/ Water Harvesting Structures (WHS) showing no plot boundary on image but multiple plots on cadastral map \& Record of Rights (ROR)
- Alteration of plot boundaries (locally) by owners

- Verification of same plot in ROR

- Encroachment of land (Temple/ Trust board land, canal and road side, Government land) for which cadastral plot boundary and image boundary not matching

- Water channel (disused) encroached by nearby plot owners.

- Cadastral map showing two plots but on the image it is one plot

- Cadastral map showing one plot but on the image it is two plot

- Boundary plot (village boundary) truncated due to acquisition of adjacent plot of another village by same owner and subsequent removal of common boundary

- Village boundary (boundary plot) vector changed after construction of Water Harvesting Structures (WHS)

- Linear measurements in two villages to check the map accuracy

- Sample DGPS observation on plot corner (vertices) and post plotting for accuracy checking

- Ground truth on zero fill parcels, part/divide /Joint parcels were undertaken and Geocoordinates were taken up using DGPS (RTK) at few checkpoints for accuracy checking.

Fig 4

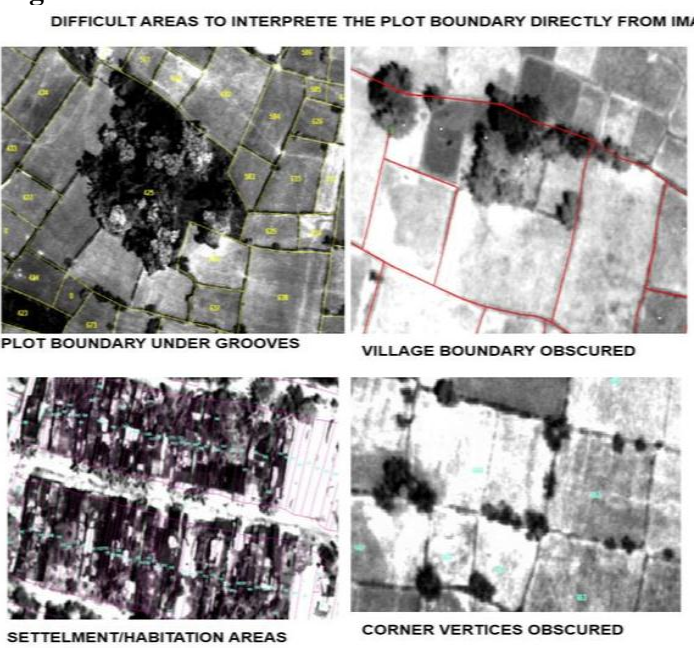

\subsection{Accuracy Checking}

Accuracy of data sets was checked in 3 steps. First step involves comparison of geo-coordinates (of randomly selected points) generated by computer with that of actually observed through DGPS. Second step involves comparison of length measurement (of tie lines) generated by computer with that of actual field measurement. Third step involves comparison of boundary measurements (of randomly selected parcels) generated from image data set with that of 
actual field measurements. The results of these three steps of accuracy checking are discussed below.

\subsection{Comparison of Geo-coordinates}

The geo-coordinates measured at random on the ortho image and the respective location on the ground by DGPS to check the accuracy as well as consistency based on the RMS of the photogrammetric block. The table below depicts geo-coordinate comparison.

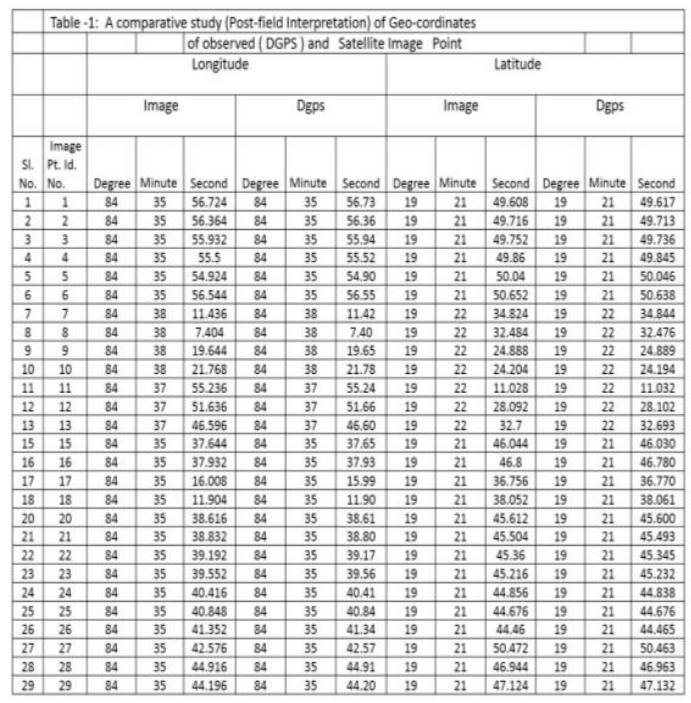

As may be observed, the measurements match up to second places after second decimal point.

\section{$5.2 \quad$ Tie line measurement}

For tie line measurement five tie lines were selected. The length of the tie line was measured from the image in GIS environment and its corresponding field measurement was done through DGPS. The results are tabulated in table-2 \& Fig-5 for comparison. The measurements were found to be matching upto third places after decimal point.

\section{Table-2 Tie-line Measurements}

\begin{tabular}{|l|l|l|l|}
\hline SI No & Line No & $\begin{array}{c}\text { Length measured } \\
\text { from Image (meter) }\end{array}$ & $\begin{array}{c}\text { Length measured } \\
\text { from Field using } \\
\text { DGPS (meter) }\end{array}$ \\
\hline 1 & 1 & 226.52274 & 226.52280 \\
\hline 2 & 2 & 1470.9126 & 1470.9130 \\
\hline 3 & 3 & 248.44296 & 248.44299 \\
\hline 4 & 4 & 725.50104 & 725.50110 \\
\hline 5 & 5 & 658.35443 & 658.35450 \\
\hline
\end{tabular}

Fig-5

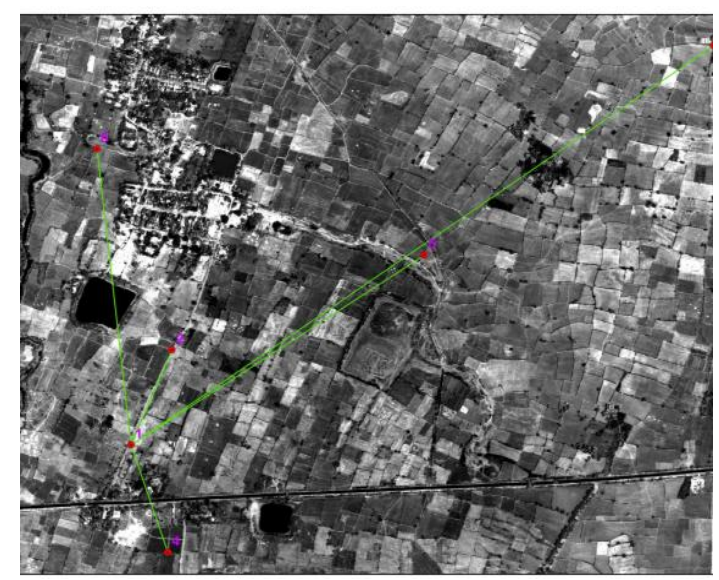

\subsection{Parcel Boundary Measurement}

Five plots in study area were randomly selected. Four sides of each of these plots were measured on the ground using meter-tape. The corresponding measurements were extracted from the image. The measurements were tabulated in the table.3 for comparison. The difference in measurements in each case is below $1 \%$.

Table-3

FELD MEASUREMENT ON SAMPLE PLOTS (RANDOM SELECTION) - GROUND DISTANCE VS. IMAGE MEASUREMENT PITAMBAPUR SASANA, MOUZA, DIGAPAHANDI TEHASIL, GANJAM DISTRICT
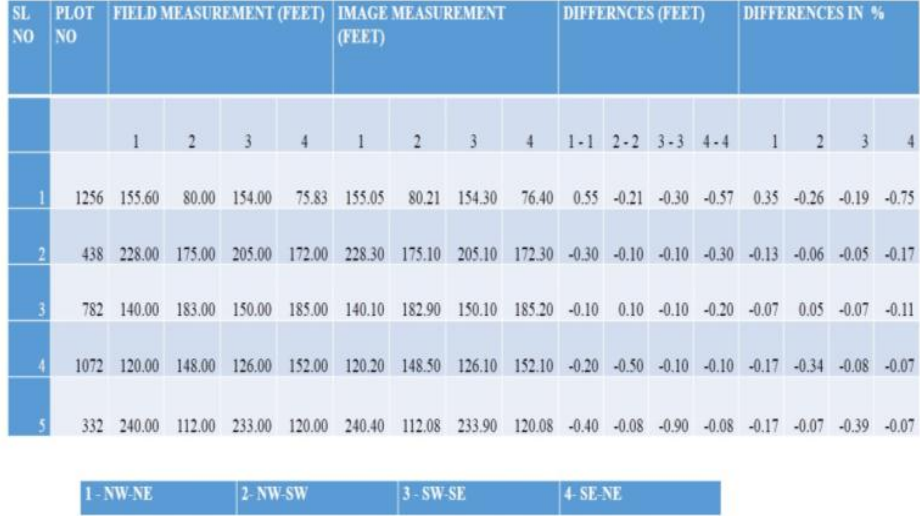

\subsection{RESULTS \& DISCUSSION}

\section{Total Area of Village- (Pitambarpur Sasan)}

$\begin{array}{ll}\text { RoR area: - } & 313.815 \text { Acre } \\ \text { Cadastral map area: - } & 315.454 \text { Acre } \\ \text { Image vector map: - } & 314.887 \text { Acre }\end{array}$

\section{No. Of Plots (Pitambarpur Sasan): -}

RoR - 1353

Cadastral map: - $\quad 1348$

Image vector map: - $\quad 1353$ 
The difference in RoR and Map (5 plots) is due to subdivision of original plots in RoR.

\section{Pitambarpur Sasan}

\begin{tabular}{lcc} 
Matched plots $(0-2 \%)$ & 1069 & $79.8 \%$ \\
Gharabari & 178 & $13.0 \%$ \\
Mismatch & 106 & $07.2 \%$ \\
\hline Total No. of Plots & 1353 & $100 \%$
\end{tabular}

\section{STANDARD/FORMAT FOR MAP \& GIS DATABASE GENERATION}

\begin{tabular}{|c|c|c|}
\hline \multicolumn{2}{|l|}{ Mapping Standards } & $1: 2,000$ \\
\hline \multicolumn{2}{|c|}{ Spatial Framework } & NSF \\
\hline \multicolumn{2}{|c|}{ Ortho rectification Accuracy (RMS) } & $0.1 \mathrm{~m}$ \\
\hline \multicolumn{2}{|c|}{ Projection } & UTM \\
\hline \multicolumn{2}{|l|}{ Datum } & WGS 84 \\
\hline \multicolumn{2}{|c|}{ Map Frame size } & One sheet \\
\hline \multicolumn{2}{|c|}{$\begin{array}{l}\text { Map (Planimetric) Accuracy } \\
\text { Minimum Mappable Unit (MMU) } \\
\text { Accuracy of Mapping }\end{array}$} & $\begin{array}{c}0.1 \mathrm{~m} \\
10 \times 10 \mathrm{~cm} \\
100 / 99\end{array}$ \\
\hline \multicolumn{2}{|c|}{ Map Format } & Digital GIS Compliance \\
\hline \multicolumn{2}{|c|}{ GIS Database Standards } & $1: 2,000$ \\
\hline \multicolumn{2}{|c|}{ Spatial framework } & Nouza \\
\hline \multicolumn{2}{|c|}{ Tie Point Intervals for Spatial Framework } & Meter grid \\
\hline \multicolumn{2}{|c|}{ Projection } & UTM \\
\hline \multicolumn{2}{|l|}{ Datum } & WGS 84 \\
\hline \multicolumn{2}{|c|}{ Minimum Frame size } & One sheets \\
\hline \multicolumn{2}{|c|}{ Tic Registration Accuracy in meters } & 0.001 \\
\hline \multicolumn{2}{|c|}{ Planimetric Accuracy (lmm of scale) in $\mathrm{m}$} & 0.02 \\
\hline \multicolumn{2}{|c|}{ Coordinate Movement Tolerance (CMT) } & $\begin{array}{l}0.00001 \\
0.001\end{array}$ \\
\hline \multicolumn{2}{|c|}{ Sliver Polygon Tolerance (SPT) } & $<0.001$ sqm \\
\hline \multicolumn{2}{|c|}{ Grid size (for Image/Raster layers) } & $100 x 100 \mathrm{~m}$ \\
\hline \multicolumn{3}{|c|}{\begin{tabular}{|l|l} 
Output Standards & $1: 2,000$ \\
\end{tabular}} \\
\hline \multirow{4}{*}{$\begin{array}{l}\text { Output Formats } \\
\text { Output Framework }\end{array}$} & \multicolumn{2}{|c|}{ Digital GIS Compliance } \\
\hline & \multicolumn{2}{|c|}{ Admin Unit - Village } \\
\hline & \multicolumn{2}{|c|}{ User defined region AOI . } \\
\hline & \multicolumn{2}{|c|}{ Spatial Framework grids } \\
\hline Output Media & \multicolumn{2}{|c|}{ CD-ROM/DVD } \\
\hline Output Projection & \multicolumn{2}{|c|}{ UTM / User defined } \\
\hline Output Datum & \multicolumn{2}{|c|}{ WGS 84} \\
\hline Output Format & \multicolumn{2}{|c|}{ GoeTiff, Shape file } \\
\hline Output Symbology & \multicolumn{2}{|c|}{ As per Layer Legend/DoLR standards } \\
\hline
\end{tabular}

\subsection{CONCLUSION}

High-resolution space-borne remote sensing image data show a high level of detail and provide many opportunities to be used as base for cadastral map generation. Ortho images generated by using satellite data having $0.5 \mathrm{~m}$ spatial resolution are ideally suited for deriving cadastral plot vectors for plain areas. The obscured areas need ground survey intervention by DGPS \& ETS. The habitation area vectors (very small polygons which cannot be resolved through $0.5 \mathrm{~m}$ data) of existing cadastral maps can be integrated to image vector maps to finalise the new cadastral maps of the villages. The image derived cadastral maps can be directly used by revenue official for tenant interaction, settlement activities and revenue administration.

One of the significant observations of the study is matching of Total village area in Cadastral map area (after digitization), the image map of 2009 and RoR area.
The final cadastral map generated (fig. 6) by Hightech survey provides accurate matching of plot areas in $81 \%$ of plots. In total $80 \%$ of plots in both the villages derived by high-tech survey method shows acceptable level of accuracy considering the fact that the mode of area measurement by ground and automated method has significant variability. Including the Gharabari plots the total plot area in 95\% (within 0-2\% variations) of plots are matching with existing RoR.

It is also observed that the plot area of digitized cadastral map and the image map are matching but in case of certain plots the RoR area shows wide variation. The variation is more in case of Government lands, Temple/Trust lands, Common Property Resources and plots near to Village boundary etc. as the tenants trespassed to the vacant Govt. lands.

The adopted technology can be successfully used for Cadastral Resurvey and Cadastral GIS generation for plain areas of the state.

\section{Fig 6}

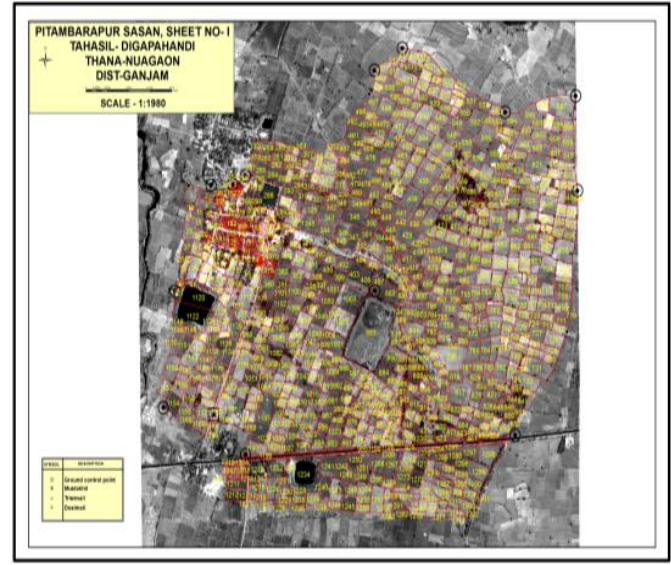

\section{ACKKNOWLEDGEMENTS}

The authors would like to express their gratitude to Additional Chief Secretary to Govt. of Odisha, Revenue \& Disaster Management and Director Land Records. Odisha for their support and encouragement during the project execution. Authors are also thankful to the engineering and technical personnel, ORSAC used for field survey as well as laboratory processing work during carrying out this study.

\section{REFERENCES}

Siva Subramanian KS, Amitabh $\mathrm{S}$ and Manda $\mathrm{S}$ (2003) Evaluation of Digital elevation models created from different satellite images. Proceedings of Map India Conference 2003, New Delhi, India, Jan 2003 
Jacobsen K (2003) Orthoimages and DEMs by QuickBird and Ikonos. Proceedings of EARSeL "Remote Sensing in Transition", Ghent: $513-525$

Jayaprasad P, Narender B, Pathan SK and Ajai Generation and validation of DEM using SAR interferometry and differential GPS supported by multispectral optical data, Journal of the Indian Society of Remote Sensing 36 (4): 313-322

Satirapod C, Rizos C and Wang J (2001), GPS Single Point Positioning with SA off: How accurate can we get? Survey Review, 36(282): 380386.

Clavet D, Lasserre M, and Pouliot J (1993), GPS Control for 1:50,000-Scale Topographic Mapping from Satellite Images. Photogrammetric Engineering \& Remote Sensing, 59(1): 107-111

Wilkie DS (1990) GPS Location Data: An Aid to Satellite Image Analyses of Poorly Mapped Regions. International Journal of Remote Sensing, 11(4): 653-658.

Barbarella M, Mancini F and Zanni M (2003) Rectification of high resolution satellite data: evaluating accuracy for map updating. Proceedings of the ASPRS/MAPPS conference

Barbarella M, Mancini F. and Zanni M (2003) Processing of high resolution satellite data for map updating. Proceedings of 30th International Symposium on Remote Sensing of Environment, Honolulu, Hawaii, USA, Nov. 2003.

NLRMP guidelines by LRD, Dept. of Land Resources, Govt. of India 